\title{
A influência da escolaridade no processo de variação de concordância verbal na língua usada em Serra Talhada
}

\author{
The influence of scholarity in the verbal agree variation in the language used in Serra \\ Talhada
}

\author{
Juliana da Silva* \\ Universidade Federal de Pernambuco \\ Recife, Pernambuco, Brasil \\ Renata Lívia de Araújo Santos* \\ Universidade Federal Rural de Pernambuco \\ Serra Talhada, Pernambuco, Brasil
}

\begin{abstract}
Resumo: O presente artigo tem o propósito de analisar a influência da variável extralinguística escolaridade no processo de variação de concordância verbal na língua usada no sertão pernambucano. Nossa fundamentação teórica- metodológica segue os pressupostos da Sociolinguística Variacionista de Labov (2008[1972]). Os estudos variacionistas sobre a concordância verbal no português brasileiro apontam que esse fenômeno é altamente variável, e condicionado pela influência de fatores linguísticos e sociais. Neste trabalho, estamos considerando os seguintes níveis de escolaridade: o ensino fundamental, o ensino médio e o ensino superior, para que possamos verificar quais destes níveis de escolarização propiciam um favorecimento na marcação da regra de concordância verbal. Os resultados alcançados apontam um favorecimento na marcação de CV no falar serra-talhadense, sendo que a variável social escolaridade foi apontada como a segunda variável mais significativa para o nosso estudo.
\end{abstract}

Palavras-chave: Variação linguística. Concordância verbal. Escolaridade. Língua falada

\begin{abstract}
This paper have the purpose of analyze the influence of the extralinguistic scholarity variable in the verbal agree variation process in the language used in Serra Talhada. We use as theoretical and methodological support the postulates of Labov's Variationist Sociolinguistic (2008[1972]). The variationist studies about verbal agree in Brazilian Portuguese (BP) show that this phenomenon is highly variable and conditioned by the influence of social and linguistic factors. In this paper, we are taking in consideration the following scholarity degrees: elementary school, high school and college education in order to verify which of these scholarity degrees is favorable to the use of the verbal agree rule. The results show us that the use of verbal agree were highly favored, and, in our study, the second most significant variable for that use of verbal agree was the scholarity.
\end{abstract}

Keywords: Linguistic variation. Verbal agree. Scholarity. Spoken language

* Mestranda em Linguística pel Universidade Federal de Pernambuco, bolsista CAPES. E-mail: julianasilvaletras@gmail.com

** Doutora em Linguística pela Universidade Federal de Alagoas Professora da Universidade Federal Rural de Pernambuco, Unidade Acadêmica de Serra Talhada - PE, Brasil. E-mail: renatalivia@gmail.com 


\section{INTRODUÇÃO}

O presente trabalho tem como objetivo investigar a influência da escolaridade e as suas possíveis implicações para o processo de variação de concordância verbal (CV), para isso, apresentamos um recorte dos resultados obtidos no projeto "a língua falada em Serra Talhada: um estudo variacionista sobre a concordância verbal". Este projeto foi desenvolvido entre os anos de 2013 a 2016 na Universidade Federal Rural de Pernambuco, Unidade Acadêmica de Serra Talhada.

Para estudar a língua falada nesta comunidade, partimos do estudo da concordância verbal, mais especificamente, a variação de concordância verbal, desse modo focaremos na relação entre escolaridade e concordância.

Os estudos variacionista sobre a concordância verbal demonstram que para as diferentes regiões que constituem o nosso pais, esse fenômeno é altamente variável. Para a exemplificação da variação desse fenômeno, apresentamos os seguintes exemplos:

(1) Os politicos vivem de férias

(2) Os políticos vive de férias

(3) Nós ficamos no meio do nordeste

(4) Nós fica no meio do nordeste

Nos exemplos (1) e (2), em que o sujeito encontra-se em itálico e o verbo em negrito, notamos uma alternância entre a marcação e não marcação de $\mathrm{CV}$, sendo que, em (1), temos a presença de marcas de CV; já em (2), temos ausência dessas marcas. Notamos que esta alternância está condicionada ao tipo de sujeito da sentença, e também, a influência da variável linguística saliência fônica.

As construções de número (3) e (4) estão relacionadas com a variação da concordância com a expressão de primeira pessoa do plural (nós). Nestas construções, percebemos que essa alternância no uso da $\mathrm{CV}$, está relacionada com a natureza do sujeito em questão.

A concordância verbal configura-se como um fenômeno altamente variável no Português Brasileiro, ou seja, uma regra variável que abrange duas variantes, presença e ausência de marcas de CV, e que é muito produtiva. Para este trabalho, estamos partindo da hipótese de que há ocorrência de variação entre ausência e presença de marcas de CV, sendo essa variação condicionada por fatores linguísticos, tais como a saliência fônica, a natureza do sujeito e a distância do sujeito e o verbo, e por fatores extralinguísticos, tais como a escolaridade, a faixa etária e o sexo.

A sociolinguística tem como principal objetivo estudar a variação e a mudança linguística na língua em uso das diferentes comunidades de fala, buscando entender quais são os principais fatores que condicionam a variação de um dado fenômeno linguístico, e analisando se posteriormente essa variação pode ou não evoluir para uma mudança no sistema linguístico.

A comunidade de fala escolhida para o nosso estudo corresponde ao município de Serra Talhada, que está localizado a $415 \mathrm{~km}$ da capital Recife. De acordo com os dados 
do último Cesno do IBGE, Serra Talhada possui uma população estimada em 84,970 habitantes, e, de acordo com as informações cedidas pela Agência Estadual de Planejamento e Pesquisas de Pernambuco (CONDEPE/FIDEM), é responsável pelo $8^{\circ}$ lugar no ranking dos municípios que lideram os maiores PIB's do sertão do estado de Pernambuco, o que potencializa investimentos econômicos na região.

Nesse sentido, esperamos que este trabalho contribua para o desenvolvimento de novas pesquisa no interior do sertão de Pernambuco, ressaltando assim a relevância social deste fenômeno, e estimulando a realização de novas pesquisa sobre concordância.

O presente artigo está dividido em cinco seções. Na primeira seção, tecemos reflexões sobre a influência dos fatores sociais, mais especificamente, a escolaridade e a faixa etária. Na segunda seção, fazemos uma breve síntese dos estudos realizados sobre a concordância verbal. $\mathrm{Na}$ terceira seção, procuramos fazer uma reflexão sobre a comunidade de fala investigada. $\mathrm{Na}$ quarta seção, apresentamos os procedimentos metodológicos adotados neste estudo. Por último, na seção de análise, teceremos nossas considerações em relação aos resultados alcançados.

\section{A INFLUÊNCIA DOS FATORES SOCIAIS: ESCOLARIDADE E FAIXA ETÁRIA}

O controle dos fatores sociais dentro de uma pesquisa em sociolinguística está relacionado com a representatividade da comunidade de fala, ou seja, reflete a estratificação social de uma determinada sociedade.

Sabemos que a atuação dos fatores sociais clássicos, como a faixa etária, a escolaridade, e sexo/gênero estão diretamente relacionados como a metodologia adotada na pesquisa, e a relevância desses fatores, estão relacionados com as escolhas metodológicas de delimitação da comunidade de fala em estudo.

A atuação da variável faixa etária como um fator condicionador para os processos de variação e mudança linguística é algo recorrente dentro dos estudos sociolinguísticos. Dessa forma, devemos compreender a mudança linguística como um processo de evolução da língua, que leva anos para ser consolidada no sistema linguístico, e que precisa passar pela avaliação dos usuários da língua.

Dizemos que ocorre uma mudança linguística, quando há um processo de variação instável, também denominada como uma mudança em progresso.

Para constatarmos se um determinado fenômeno linguístico se encontra em processo de variação estável ou mudança em progresso, é necessário consideramos aspectos sincrônicos e diacrônicos a partir de uma divisão temporal, ou seja, devemos fazer a distinção entre tempo aparente e tempo real.

A mudança linguística em tempo aparente tem como base a distribuição em faixa etárias, a partir de uma amostra sincrônica, onde será observada as ocorrências de variação nas diferentes faixas etárias, tentando observar uma possível direção para a mudança.

Os resultados de uma mudança linguística em tempo aparente podem indicar uma mudança de comportamento linguístico que se repete a cada geração, o que chamamos 
de gradação etária, ou os resultados podem apontar para uma mudança em progresso, onde as pessoas mais jovens farão o uso de maior frequência de formas inovadoras, em relação aos indivíduos mais velhos.

$\mathrm{Na}$ mudança linguística em tempo real teremos uma observação da comunidade de fala em diferentes momentos de sua história, onde observamos a evolução linguística de uma determinada forma que esteja em variação através do tempo. De acordo com Cezário e Votre (2008) trata-se de um estudo de dois momentos que se distanciam no mínimo em 12 anos e no máximo em 50 anos, ou seja, trata-se de um estudo que vai estudar a variação a partir de recorte de tempos distintos.

Freitag (2011) elenca uma série de fatores que devem ser considerados ao escolhermos a variável faixa etária: 1) características da constituição da amostra; 2) as entrevistas sociolinguísticas; 3) indivíduos que produzem poucas narrativas, o que pode influenciar na qualidade dos resultados; 4) a relação entre faixa etária e papéis sociais.

A variável faixa etária deve ser vista pela sua complexidade, cabendo ao pesquisador um extremo cuidado ao traçar as faixas etária de uma determinada pesquisa, deve-se haver um tempo de intervalo entre as faixas etárias, para que as mesmas possam ser representativas da comunidade de fala.

Levando em consideração que essa variável é altamente complexa, por está diretamente relacionada com os processos de mudança linguística. De acordo com Freitag (2005, p. 111), "A faixa etária é apenas um rótulo que agrupa vários fatores de ordem social e biológica do indivíduo". Essa variável é responsável pelas diferentes mudanças ocorridas no percurso do nosso ciclo de vida.

As generalizações em relação a essa variável devem levar em consideração os aspectos sociais, biológicos que permeiam o comportamento linguístico dos falantes., cabendo ao pesquisador responsabilidade para identificar os processos de variação e mudança linguística, pois nem todo indício de variação acarreta numa mudança no sistema linguístico.

A variável escolaridade, também denominada de escolarização têm sido amplamente discutidas pelos sociolinguistas. Esse interesse, ressalta a relevância dessa variável no estudo de diferentes fenômenos linguísticos.

O indivíduo de pouca cultura formal possivelmente só chegará a ter consciência do caráter estigmatizado da concordância não-padrão depois de um período de escolarização e de convívio com o dialeto de classe média urbana. A duração deste período não é possível de se precisar, sem que se proceda a estudos experimentais. Podemos, porém, prever que esse indivíduo adotará a certa altura de sua formação escolar supletiva as normas de avaliação da classe mais alta, mas tenderá sempre a usar a regra de concordância padrão com menos frequência, posto que ele a assimilou tardiamente. (BORTONI-RICARDO, 1981, p. 94). 
Observa-se que o indivíduo tende a assimilar as regras de concordância conforme o tempo de exposição ao ambiente escolar, sendo a escola responsável pelos padrões das normas. A ausência da regra de concordância verbal tende a desencadear atitudes de preconceito linguístico dentro do espaço escolar.

A escola como uma força controladora da norma padrão, exerce influência significativa sobre o repertorio linguístico dos indivíduos, entretanto as diferenças linguísticas que muitas vezes são tratadas pela escola como desvios, são reflexos das diferenças sociais.

Assim, percebemos que a escola ao longo dos anos, vêm passando por transformações, transformações essa, ligadas a reformas na educação no Brasil. Ao levarmos em consideração os anos de escolarização dos informantes de uma determinada pesquisa, alguns questionamentos devem ser feitos, como os níveis de escolaridades podem ser os mesmos, se ao longo dos anos tivemos várias transformações e avanços na educação, até mesmo em relação ao status que a escola representa atualmente.

É necessário pontuarmos, que existem outros aspectos que devem ser levados em consideração, ao trabalharmos coma variável escolaridade, são eles: a classe social, as oportunidades de ensino, a escolarização dos pais, os hábitos de leitura e a profissão dos pais. Esses aspectos influenciam no comportamento social dos indivíduos afetando os relacionamentos no ambiente escolar.

Assim, podemos afirmar que a escola tem um papel fundamental para o uso da regra de concordância padrão, tratando-se de uma variável complexa, tendo em vista que outros fatores sociais devem ser considerados.

Obviamente a escola exerce pressão significativa para a manutenção das formas de prestigio, o que contribui para estigmatização de variedades linguísticas desprestigiadas, ocasionando atitudes de preconceito linguístico, algo que deveria ser desconstruído dentro do ambiente escolar.

Nesse sentido, as discussões propostas nesta seção abrem caminho para questionamentos em relação ao controle das variáveis sociais faixa etária e escolaridade. Acreditamos que a escolaridade constitui um fator extralinguístico significativo para o favorecimento da regra de CV.

\section{DELIMITAÇÃO DO TEMA}

Um tema que vem despertando o interesse dos estudiosos da linguagem é a variação de concordância verbal, interesse esse que está diretamente relacionado a sua natureza variável, ou seja, os indivíduos oscilam entre a marcação e não marcação de $\mathrm{CV}$, demonstrando assim, as variações no uso da $\mathrm{CV}$. 
Os estudos variacionistas sobre a concordância verbal, no Brasil começaram por volta da década de setenta. Os pesquisadores Anthony Naro, Miriam Lemle e Marta Scherre são considerados os pioneiros nesses estudos. Esses trabalhos serviram de pontapé inicial para uma vasta literatura que encontramos atualmente sobre o tema.

Para Abreu (2003, p.171), "a concordância verbal é um processo pelo qual, dentro de uma oração, o verbo assume os traços de número e pessoa do sujeito". Podemos notar, que essa abordagem prescritiva da gramática tradicional em relação a concordância verbal, está fixada em uma regra, que não evidencia os diferentes usos linguísticos. A abordagem sociolinguística desse fenômeno demonstra que essa regra é altamente variável, e condicionada pela influência de fatores linguísticos e extralinguísticos. Considerando o componente diatópico, passamos a apresentar estudos sobre a concordância verbal realizados na região Nordeste.

Em um trabalho intitulado $A$ concordancia verbal na fala de menores carentes que vivem em entidades filantrópicas de Maceió, Santos (2010) analisa a fala de crianças e adolescentes que vivem entidades filantrópicas, afim de verificar se há variação entre ausência e presença de marcas de CV. No trabalho de Santos, foram selecionados 16 informantes das entidades filantrópicas: Lar Batista Marcolina Magalhães e Lar evangélico masculino pastor.

De modo geral, os resultados obtidos no estudo de Santos apontaram para a variação de $C V$, sendo a variante presença de marcas de $C V$, a mais recorrente na fala desses informantes. As variáveis linguísticas selecionadas como significativa para o estudo foram: número/pessoa, ausência e presença de elementos intervenientes na relação entre sujeito e verbo, tempo de permanência na entidade filantrópica e a posição do sujeito em relação ao verbo. Em relação as variáveis sociais, a variável escolaridade foi a única apontada como bastante significativa para a pesquisa.

Outro trabalho que também investiga o uso variável de concordância verbal referese ao estudo de Silva (2015). Nesse trabalho, a autora analisa os aspectos sintáticos do Português Falado em Pernambuco a partir de uma pesquisa realizada entre os anos de 2007 a 2009. O estudo realizado por Silva (2015) contribui para o desvendamento da realidade sociolinguística de comunidades de fala do interior de Pernambuco, caracterizando assim, o comportamento linguístico desses falantes em relação à regra de CV.

Ao investigar o fenômeno variável da concordância, a pesquisadora parte da hipótese de que a influência de "fatores linguísticos e extralinguísticos parecem favorecer a ocorrência de formas não padrão na língua falada das duas localidades do alto sertão do Pajeú" (SILVA, 2015, p. 232). O corpus do trabalho é constituído pelas gravações de falas de 36 informantes, sendo 24 informantes do município de Serra Talhada e 12 informantes de Bernardo Vieira.

Para a realização do estudo, foram controladas às seguintes variáveis sociais: o sexo (masculino e feminino), o nível de escolaridade (fundamental e médio), a faixa etária (15 a 25 anos e 26 a 49 anos) e a renda familiar de até dois salários mínimos. Em relação às variáveis linguísticas investigadas temos: a saliência fônica, a posição do sujeito e o tipo de verbo. 
Abaixo, apresentamos os resultados dos fatores extralinguísticos que foram considerados como significativos no trabalho de Silva. Ressaltamos ainda, que não teremos como tecer discussões mais aprofundadas em relação ao fenômeno, pois não tivemos acesso aos resultados de todas as variáveis analisadas nesse estudo. Esses resultados encontram-se simplificados, não houve a divulgação dos números de ocorrências das variáveis postas em análise.

\begin{tabular}{lll}
\hline Renda familiar & Bernardo Vieira & Serra Talhada \\
\hline Até dois salários & $85 \%$ & $95 \%$ \\
\hline Nível médio & $90 \%$ & $85 \%$ \\
\hline Sexo masculino & $82 \%$ & $92 \%$
\end{tabular}

Tabela 1: Resultados dos fatores extralinguísticos em relação a variante padrão nas duas comunidades estudadas Fonte: SILVA, 2015, p. 235

Observamos que os fatores sociais, renda familiar até dois salários, nível médio e o sexo masculino concentram a maior parte das ocorrências de aplicação da variante padrão em ambas as comunidades analisadas. Os resultados percentuais do Distrito de Bernardo Vieira demonstraram que a escolaridade, mais especificamente, o ensino médio obteve um percentual maior, em relação aos demais fatores sociais. Em relação aos resultados da comunidade de fala de Serra Talhada, percebemos que a renda familiar (até dois salários mínimos) obteve um percentual maior no uso da variante padrão, destacando-se também o sexo masculino.

Encontramos exposto abaixo, os resultados referentes aos fatores linguísticos de ambas as comunidades investigadas no estudo de Silva (2015).

\begin{tabular}{lll} 
& Bernardo Vieira & Serra Talhada \\
\hline Verbos mais salientes & $50,5 \%$ & $60 \%$ \\
\hline Sujeito simples & $79 \%$ & $80 \%$ \\
\hline Sujeito imediatamente antes do verbo & $85,5 \%$ & $55,25 \%$ \\
\hline
\end{tabular}

Tabela 2: Resultados dos fatores linguística em relação ao uso do variante padrão Fonte: SILVA, 2015, p. 235.

Os resultados das variáveis linguísticas mostraram um comportamento similar em ambas localidades, pois foram selecionados os mesmos fatores em relação à aplicação da variante padrão (CV). Dessa forma, as variáveis linguísticas selecionadas como significativas no trabalho de Silva foram: a saliência fônica (verbos mais salientes); o tipo de sujeito (sujeito simples), a posição do sujeito (sujeito imediatamente antes do verbo). Essas variáveis apontaram para o uso da variante padrão. Dessa forma, as variáveis linguísticas selecionadas como significativas no trabalho de Silva foram: a saliência fônica (verbos mais salientes); o tipo de sujeito (sujeito simples), a posição do sujeito (sujeito imediatamente antes do verbo). Essas variáveis apontaram para o uso do variante padrão. 
Os resultados do trabalho de Silva demonstraram que apesar das duas localidades apresentarem perfis sociais distintos, e por estarem localizadas em áreas diferentes, em relação à concordância verbal, foi obtido um uso variável em ambas localidades.

Ressaltamos a relevância do trabalho de Silva (2015), o que vem a contribuir para a nossa investigação e também para a divulgação de trabalhos que retratam o perfil linguístico de comunidade de fala do interior do sertão nordestino.

\section{COMUNIDADE PESQUISADA}

Assumimos o conceito de comunidade de fala adotado por Labov em seus estudos, conforme está descrito abaixo.

A comunidade de fala não é definida por nenhuma concordância marcada no uso de elementos linguísticos, mas sim, pela participação num conjunto de normas compartilhadas; estas normas podem ser observadas em tipos de comportamento avaliativo explicito e pela uniformidade de padrões abstratos de variação que são invariantes no tocante a níveis particulares de uso. (LABOV, 2008, p.150).

Visando estudar a língua falada nesta comunidade, acreditamos que é impossível compreender o processo de variação linguística fora do contexto social de uma comunidade fala, dessa forma, a comunidade de fala passa a ser esse espaço marcado pela heterogeneidade social.

A cidade possui uma visibilidade no cenário nacional por ser considerada a terra de Lampião. Inserida na mesorregião do sertão de Pernambuco, Serra Talhada juntamente com outras dezesseis cidades constituem a microrregião do sertão do Pajeú.

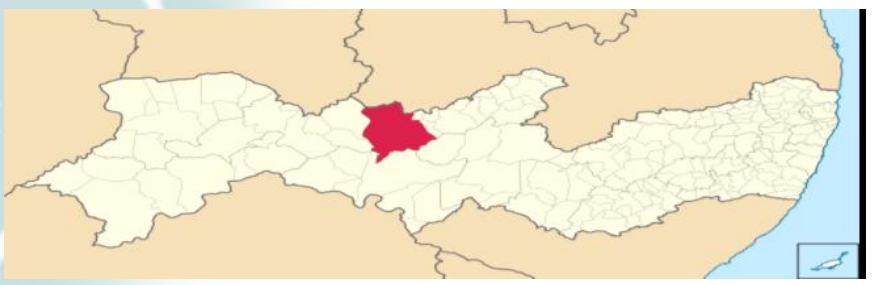

Mapa 1: Localização de Serra Talhada em Pernambuco Fonte: https://pt.wikipedia.org/wiki/Serra_Talhada

Atualmente Serra Talhada é reconhecida pelos investimentos na área educacional, são cento e doze escolas municipais, dez estaduais e treze privadas ${ }^{1}$. Desse total, podemos encontrar 10 escolas que ofertam o ensino médio na região. Temos duas escolas estaduais de referência no ensino médio, são elas: Cornélio Soares e Prof. Adauto Carvalho.

1 Essas informações foram obtidas através do site da prefeitura de Serra Talhada. 


\begin{tabular}{|l|l|l|}
\hline \multicolumn{1}{|c|}{ Escolas } & $\begin{array}{c}\text { Dependência } \\
\text { administrativa }\end{array}$ & \multicolumn{1}{|c|}{$\begin{array}{c}\text { Média do } \\
\text { ENEM 2015 }\end{array}$} \\
\hline EREM Professor Adauto Carvalho & Estadual & 529,42 \\
\hline Escola Estadual Irnero Ignácio & Estadual & 478,72 \\
\hline Escola de Referência em Ensino Médio Cornélio Soares & Estadual & 496,26 \\
\hline Colégio da Imaculada Conceição & Privada & 553,90 \\
\hline Colégio aplicação & Privada & 573,52 \\
\hline Escola Manoel Pereira Lins & Municipal & 464,62 \\
\hline Escola Técnica Estadual Clovis Nogueira Alves & Federal & 510,18 \\
\hline
\end{tabular}

Quadro 1: Distribuição da Média do Enem das escolas de ensino médio em Serra Talhada Fonte: Instituto Nacional de Estudos e Pesquisas Educacionais Anísio Teixeira

Observamos que resultados da rede privada apontam para uma maior média do Colégio Aplicação $(573,52)$ e da Escola Imaculada Conceição $(553,90)$. Já os resultados da rede estadual apontam para a Escola de Referência Professor Adauto Carvalho (Erempac), essa escola se destacou entre as 20 melhores notas de Pernambuco no Exame Nacional do Ensino Médio no ano 2015.

Em Pernambuco, Serra Talhada está se destacando com a aprovação dos estudantes em diferentes universidades, de acordo com Ranking do Enem 04 escolas de Serra Talhada estão entre as melhores do sertão do Pajeú.

Esses resultados positivos ressaltam a atuação dos coordenadores e professores das redes públicas que intensificam a construção do conhecimento, apesar de todas as dificuldades relacionadas ao ensino público, destacando-se a atuação dos alunos dessas escolas.

Salientamos ainda, que os informantes entrevistados nesse trabalho obtiveram formação escolar nas escolas da rede pública, sendo que o ensino fundamental foi concluído em escolas da rede municipal e o ensino médio em escolas da rede estadual.

O município também se destaca pela inserção de instituições federais de ensino superior, o que vem a contribuir com a vinda de estudantes de diferentes localidades. As universidades contribuiram para a expansão da escolaridade na região, aumentando assim, a demanda na oferta de ensino, ocasionando oportunidade de estudo para os moradores do interior do sertão de Pernambuco e de demais regiões vizinhas.

Entre as instituições públicas de ensino instaladas em Serra Talhada, podemos citar as seguintes: 1) Unidade Acadêmica de Serra Talhada (UAST/UFRPE); 2) Universidade de Pernambuco (UPE); 3) Instituto Federal do Sertão de Pernambuco (campus Serra Talhada).

Atualmente o município possui duas universidades federais, a primeira universidade que se instalou no município foi a Universidade Federal Rural de Pernambuco (UFRPE), mais especificamente a Unidade Acadêmica de Serra Talhada (UAST), no ano de 2006. Recentemente, há aproximadamente dois anos, foi construída a Universidade de Pernambuco (UPE), além de possuir também faculdades particulares e outros polos de ensino à distância. Em relação às faculdades particulares destacamos a Faculdade de Integração do Sertão (FIS) e a Faculdade de Formação de Professores de Serra Talhada (FAFOPST). 
Acreditamos que essas características, o intenso contato com pessoas de diferentes regiões e o processo de escolarização são de fundamental importância para a construção do perfil social da referida comunidade, essas características fazem de Serra Talhada, a cidade mais importante do interior de Pernambuco.

\section{PROCEDIMENTOS METODOLÓGICOS}

Seguimos os pressupostos da metodologia quantitativa da Sociolinguística Variacionista (LABOV, 2008 [1972]), que apresenta um passo a passo consistente no tratamento dos dados linguísticos.

Para estudar a fala desta comunidade foram selecionados 54 informantes naturais de Serra Talhada ou que vivem na localidade a mais de cinco anos, estes foram distribuídos de igual proporção, de forma aleatória estratificada de acordo com o sexo (masculino e feminino), a escolaridade (ensino fundamental, ensino médio e ensino superior) e a faixa etária (15 a 29 anos), 30 a 44 anos, e mais de 44 anos).

Antes de partir para a coleta dos dados, é necessário pontuarmos a importância do planejamento do material, que vai auxiliar o processo de coleta. Foram elaborados para a pesquisa os seguintes materiais: as fichas sociais, os roteiros das entrevistas e os roteiros das narrativas. As fichas sociais são estruturadas a partir de informações de caráter pessoal e social, essas fichas auxiliam o investigador, pois atuam como espécie de cadastro social dos informantes. Dependendo do tipo de pesquisa, essas fichas podem variar, cabe ao pesquisador escolher as perguntas mais relevantes para o trabalho

As entrevistas sociolinguísticas foram arquitetadas a partir de um roteiro de perguntas e respostas que abrangiam temas diferentes do cotidiano, perguntas relacionadas à rotina do informante, perguntas direcionadas ao atendimento em órgão público, dentre outras perguntas

Para o nosso trabalho, essas entrevistas funcionaram, a princípio, como uma estratégia, para que o informante se acostumasse com a presença do pesquisador e não se policiasse, ou seja, não monitorasse a fala, pois tínhamos como interesse captar a fala mais espontânea possível. O entrevistador deve tomar alguns cuidados para não constranger o informante durante a gravação, adotando sempre, uma postura ética diante das informações que estão sendo relatadas

Foram coletadas as falas dos 54 informantes por meio de entrevistas e narrativas orais. Nossas entrevistas e narrativas tiveram a duração entre 4 e 10 minutos, tentando manter uma uniformidade em relação ao tempo.

As narrativas tinham como foco três temas, que foram os mesmos para todos os informantes do estudo. No primeiro tema o informante poderia discutir aspectos que tivessem relacionado à comunidade de fala, temas relacionados à cidade, a educação ou a política. O informante ficaria à vontade para abordar qualquer temática, desde que essa temática estivesse relacionada ao município de Serra Talhada. O segundo tema das narrativas foi "perigo de vida", onde o informante contaria se passou por alguma situação de risco. Esse tema, "perigo de vida", segundo Labov (2008), proporciona o envolvimento emocional do entrevistado, dessa forma, eles esquecem que estão sendo gravados, e 
acabam não se monitorando. O terceiro tema corresponde à família, onde esperávamos que o informante falasse da importância da família, da sua relação com os outros membros da família, como também, poderia falar de um dia especial, dentre outros aspectos

Em seguida prosseguimos com a transcrição dos dados linguísticos, de acordo com as normas de transcrição adotadas no modelo utilizado no Programa de Estudos Linguísticos (PRELIN) da Universidade Federal de Alagoas.

$\mathrm{Na}$ segunda parte metodológica realizamos as codificações dos dados, e o manuseio do programa computacional Goldvarb-X, o qual nos possibilitou o tratamento estatísticos dos dados. E por último, apresentamos uma análise dos resultados gerais obtidos na pesquisa.

\section{ANÁLISE DOS DADOS}

Foram analisadas 897 sentenças de sete grupos de fatores linguísticos e extralinguísticos, através do programa computacional Goldvarb-X.

Em nossa análise, iremos retomar os resultados gerais das variáveis linguísticas e extralinguísticas postas em análise, tendo em vista que esses resultados contribuem para uma melhor descrição do fenômeno.

De acordo com Vieira e Brandão (2014), os vários estudos sobre concordância verbal já apontam que “o fenômeno é amplamente variável no PB". Esses estudos vêm demostrando que os padrões de concordância estão diretamente relacionados a atuação de fatores linguísticos e extralinguísticos. E no caso específico da concordância verbal, percebemos que esse padrão é fortemente marcado nas comunidades mais escolarizadas.

Conforme vemos no gráfico abaixo, os resultados iniciais apontam um favorecimento para aplicação da regra de CV (66\%), em oposição a não aplicação (34\%).

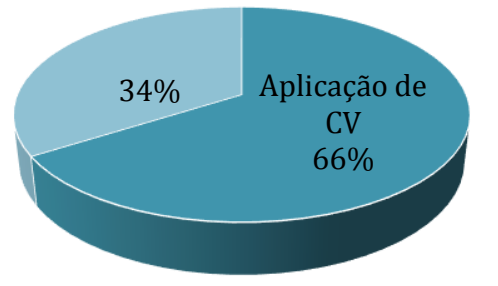

- Aplicação de CV Não aplicação

Gráfico 1: Resultados gerais sobre o uso de concordância verbal em Serra Talhada.

De acordo com o primeiro gráfico, percebemos que na comunidade de fala aqui estudada, houve um maior percentual (66\%) para aplicação de CV, já para não aplicação de $\mathrm{CV}$, obtivemos um percentual de $(34 \%)$. Os nossos resultados corroboram com resultados gerais obtidos por Silva (2015), ambos levaram a marcação da variante padrão.

Dessa forma, os percentuais demonstraram que houve uma variação no uso da CV na língua falada em Serra Talhada, e que a variável aplicação de CV se sobressaiu estatisticamente. 
As variáveis independentes linguísticas e extralinguísticas controladas em nosso estudos são: 1) saliência fônica (maior diferença, menor diferença); 2) distância entre sujeito e verbo (sujeito adjacente, sujeito não adjacente); 3) natureza do sujeito (Sujeito nominal, $1^{\mathrm{a}}$ pessoa do plural, $3^{\mathrm{a}}$ pessoa do plural, expressão pronominal a gente); 4) escolaridade (ensino fundamental, ensino médio, ensino superior); 5) faixa etária (15 a 29, 30 a 44, mais de 44 anos); 6) sexo (masculino e feminino).

Para compreendermos os resultados gerais que levaram a variação de CV na fala da referida comunidade, apresentaremos as variáveis que foram consideradas significativas para nosso estudo, seguindo a ordem de relevância do Goldvarb-x.

\subsection{NATUREZA DO SUJEITO}

A variável linguística natureza do sujeito foi a primeira variável selecionada pelo Goldvarb-X como a mais relevante no uso da variação das marcas de concordância verbal na comunidade de fala de Serra Talhada. Temos a seguinte hipótese para essa variável: que quanto mais o sujeito apresentar marcas de plural mais comum será de estabelecer a regra de $\mathrm{CV}$, e que o sujeito pronominal a gente levaria a mais marcas de concordância, se comparados com as demais naturezas de sujeito (sujeito nominal; sujeito pronominal $1^{\mathrm{a}}$ pessoa do plural; sujeito pronominal $3^{\mathrm{a}}$ pessoa do plural).

$\begin{array}{llc}\text { Natureza do sujeito } & \text { Aplicação/total/\% } & \text { Peso relativo } \\ \text { Sujeito nominal } & 265 / 504 / 53 \% & .30 \\ \mathbf{1}^{\mathrm{a}} \text { pessoa do plural } & 82 / 100 / 82 \% & .64 \\ \mathbf{3}^{\mathrm{a}} \text { pessoa do plural } & 109 / 155 / 70 \% & .51 \\ \text { Sujeito pronominal a gente } & 133 / 138 / 96 \% & .93\end{array}$

Tabela 3: Resultados gerais da variável linguística natureza do sujeito

Na tabela acima, podemos ver não só estatisticamente como também através dos pesos relativos o quanto essa variável linguística é significativa para a aplicação de CV. Comparando os pesos relativos percebemos que o sujeito pronominal a gente obteve um peso relativo de (.93); já o sujeito pronominal $1^{\mathrm{a}}$ pessoa do plural teve um peso relativo de (.64), e o sujeito pronominal $3^{\text {a }}$ pessoa do plural apresentou o peso relativo (.51). O único fator que apontou estatisticamente para um uso maior da não aplicação de CV foi o sujeito nominal que teve um peso relativo de (. 30).

Notamos que a natureza do sujeito pronominal "a gente" condiciona bastante o uso da regra de concordância, pois o peso relativo dessa variável é quase o peso máximo que leva ao uso das marcas de CV. Outra natureza que parece condicionar a concordância verbal é quando o sujeito se apresenta na $1^{\text {a }}$ pessoa do plural, pois tivemos um peso relativo significativo.

Tendo em vista, o exposto acima, acreditamos que a natureza do sujeito condiciona sim, a aplicação da regra de concordância nesta comunidade e confirmando assim as hipóteses aqui mencionadas. 


\subsection{ESCOLARIDADE}

A variável social escolaridade foi selecionada pelo programa Goldvarb-X, como a segunda variável significativa para a nossa pesquisa. Foram considerados os seguintes níveis de escolaridade: o ensino fundamental; o ensino médio e por último o ensino superior.

A influência da variável escolaridade é amplamente discutida pela sociolinguística, diversos estudos (SANTOS, 2015); (MONTE, 2012); (VIEIRA, 1997), apontam a sua influência sobre a regra de concordância verbal. Partimos da hipótese de que essa variável influenciaria no processo de marcação de CV.

\begin{tabular}{lll}
\hline Escolaridade & Aplicação/Total/\% & Peso relativo \\
\hline Ensino fundamental & $131 / 254 / 52 \%$ & .34 \\
Ensino médio & $196 / 306 / 64 \%$ & .45 \\
Ensino superior & $262 / 337 / 78 \%$ & .65
\end{tabular}

Tabela 4. Distribuição dos resultados gerais da variável social escolaridade

Os resultados apresentados na tabela acima confirmam a nossa hipótese de que a escolaridade é uma das variáveis sociais mais significativa quando pretendemos estudar a variação de $\mathrm{CV}$. Dessa forma, o ensino superior apresentou um peso relativo significativo para a marcação da regra de $\mathrm{CV}$, quando comparado com os demais níveis.

Dessa forma, a variável social escolaridade foi apontada pelo programa Goldvarb$\mathrm{X}$ como a segunda variável mais significativa, sendo a escolaridade uma das variáveis sociais que mais condicionam a concordância. O que se observa é que os indivíduos mais escolarizados aplicam mais concordância do que os menos escolarizados. Nas próximas etapas da pesquisa, serão realizados cruzamentos entres a variáveis escolaridade e faixa etária.

\subsection{FAIXA ETÁRIA}

A variável social faixa etária foi apontada como relevante para o nosso estudo, sendo a terceira variável selecionada pelo Goldvarb. Nesta pesquisa foram consideradas as seguintes faixas etárias: de 15 a 29 anos; de 30 a 44 anos; e mais de 44 anos, acreditamos que a faixa etária do informante pode exercer influência no processo de variação.

\begin{tabular}{ccl}
\hline Faixa etária & Aplicação/Total/\% & Peso relativo \\
\hline $\mathbf{1 5}$ a 29 anos & $224 / 308 / 73 \%$ & .61 \\
30 a 44 anos & $165 / 291 / 57 \%$ & .38 \\
Mais de 44 anos & $200 / 298 / 67 \%$ & .49
\end{tabular}

Tabela 5: Resultados gerais da variável social faixa etária

Comentando a tabela acima, percebemos que somente a faixa etária de 15 a 29 anos, apresentou um peso relativo acima de 0.55 , as demais faixas etárias não obtiveram 
resultados relevantes. Acreditamos que posteriormente nas próximas etapas de cruzamentos das variáveis possamos tecer reflexões mais aprofundadas.

\subsection{SALIÊNCIA FÔNICA}

A variável saliência fônica, que foi selecionada pelo programa, como a quarta variável linguística significativa levando em consideração a ordem de relevância. Ressaltamos que partimos da hipótese de que o princípio da saliência fônica pode influenciar na aplicação ou não da regra de CV. Neste trabalho, a variável linguística saliência fônica apresenta dois fatores: envolve maior diferença fônica na relação singular/plural; e envolve menor diferença fônica na relação singular/plural.

\begin{tabular}{lcl}
\hline Saliência fônica & Aplicação/Total/\% & Peso relativo \\
\hline Envolve maior diferença fônica & $284 / 422 / 67 \%$ & .55 \\
Envolve menor diferença fônica & $305 / 475 / 64 \%$ & .45 \\
\hline
\end{tabular}

Tabela 6: Resultados gerais da variável linguística saliência fônica

Observando os resultados da tabela acima, percebemos que apesar de percentualmente os resultados desta variável nos apontarem para um o uso da regra de $\mathrm{CV}$, ao nos depararmos com o peso relativo desta variável, notamos que ambos os fatores não apresentaram valores estatísticos significativos.

\subsection{SEXO}

Seguindo a ordem de relevância do Goldvarb-X chegamos à última variável selecionada como significativa para o presente estudo. $\mathrm{O}$ controle da variável social sexo nos indicará o comportamento linguístico de ambos os sexos em relação ao uso das marcas de CV.

Antes de apresentarmos os resultados de nossa análise, faremos algumas considerações sobre essa variável, a fim de melhor entendermos o que será exposto nesta seção.

Atualmente há uma grande discussão dentro da literatura sociolinguística sobre a variável sexo/gênero, o que vem motivado diferentes tipos de trabalhos a investigar essa variável. Para esse estudo, optamos por assumir o termo sexo, para nos referirmos aos fatores biológicos de diferenciação binária, já a palavra gênero estaria vinculada mais com a construção social desse falante. Não aprofundaremos uma discussão em relação a essa variável, porque acreditamos que esse não seja objetivo deste trabalho, mais pontuamos a importância de todos os trabalhos que investigam essa variável.

\begin{tabular}{lll}
\hline Sexo & Aplicação/Total/\% & Peso relativo \\
\hline Masculino & $277 / 444 / 62 \%$ & .45 \\
Feminino & $312 / 453 / 69 \%$ & .54 \\
\hline
\end{tabular}

Tabela 7: Resultados gerais da variável social sexo 
Vemos que, apesar de percentualmente encontramos uma pequena diferença entre o sexo masculino $(62 \%)$ e o sexo feminino $(69 \%)$, os pesos relativos já nos apontam para um sentido contrário, apontando para resultados favoráveis à marcação de $\mathrm{CV}$.

\section{CONSIDERAÇÕES FINAIS}

Neste artigo, procuramos observar a influência da variável extralinguística escolaridade no processo de variação de concordância verbal na língua usada no sertão de Pernambuco. Dessa forma, retomamos os resultados obtidos no projeto "a língua falada em Serra Talhada: um estudo Variacionista sobre a concordância verbal".

De forma geral, os resultados da comunidade de fala estudada mostram um maior percentual $(66 \%)$ para a aplicação de CV, em oposição a 34\% para não aplicação. Percebemos que a concordância verbal se apresenta como uma regra variável nesta comunidade de fala, e que o uso desta regra sofre influência de fatores internos e externos a língua.

Os resultados da variável social escolaridade evidenciam que quanto maior for a escolaridade de um falante, maior será o favorecimento da regra de CV. O ensino superior obteve um peso relativo de (0.65), que é considerado um peso significativo, favorecendo assim a aplicação de CV. Já o ensino fundamental e o ensino médio obtiveram pesos não significativos, pois não levam a aplicação da regra de $\mathrm{CV}$.

Por fim, esperamos que este estudo venha a contribuir para um mapeamento sociolinguístico do uso de concordância verbal no sertão de Pernambuco, evidenciando assim, a diversidade linguística da nossa região.

\section{REFERÊNCIAS}

ABREU, A. S. Gramática mínima: para o domínio da língua padrão. Cotia, São Paulo: Ateliê Editorial, 2013.

ARAÚJO, S. S. F. A concordância verbal no português falado em Feira de Santana BA: sociolinguística e sócio-história do português brasileiro. 2014. 342f. Tese (Doutorado em Linguística). Instituto de Letras, Universidade Federal da Bahia, Bahia, 2014.

BORTONI-RICARDO, S. M. A concordância verbal em português: um estudo de sua significação social. In: COUTO, H. H. (Ed.). Ensaios de linguística aplicada ao português. Brasília: Thesaurus, 1981. p. 79-101

FREITAG, R. M. K. Idade uma variável sociolinguística complexa. Linguas \& Letras, v. 6, p. 105-12, 2005.

FREITAG, R. M. K. O social da sociolinguística: o controle de fatores sociais. Revista Diadorim, v. 8, p. 43-58, 2011.

LABOV, W. Padrões sociolinguísticos. Trad. Marcos Bagno, Maria Marta Pereira Scherre e Caroline Rodrigues Cardoso. São Paulo: Parábola, 2008[1972]. 
MONTE, A. Concordância verbal e variação: um estudo descritivo comparativo do português brasileiro e do português europeu. 2012.171f. Tese (Doutorado em Linguística e Língua Portuguesa - Faculdade de Ciências e Letras, Universidade Estadual Paulista, Campus de Araraquara, 2012.

SANTOS, R. L. A. A concordância verbal na fala de menores carentes que vivem em entidades filantrópicas de Maceió. Maceió: UFAL. Dissertação (Mestrado em Linguística) - Faculdade de Letras, Universidade Federal de Alagoas, Maceió, 2010.

SANTOS, R. L. A. $A$ escolaridade e a variação de concordância verbal na língua usada por menores carentes de Maceió. Letras \& Letras, v. 31, p. 86-110, 2015

SILVA, C. R. T. Aspectos sintáticos do português falado em Pernambuco: traçando o perfil linguístico de comunidades do alto sertão do Pajeú. In: SEDRINS, A. P.; SÁ, E. J. Aspectos descritivos e sócio - histórico da lingua falada em Pernambuco. - Recife: Editora da UFRPE, 2015.

VIEIRA, S. R. A não-concordância em dialetos populares: uma regra variável. Graphos. João Pessoa, ano II, v. 2, n. 1,1997.

VIEIRA, S. R.; BRANDÃO, S. F. Tipologia de regras linguísticas e estatuto das variedades/línguas: a concordância em português. Lingüística, vol. 30 (2), p. 81-112, dezembro, 2014. 